EPIDEMIOLOGY

\title{
Association between sibship size and allergic diseases in the Glasgow Alumni Study
}

\author{
S Kinra, G Davey Smith, M Jeffreys, D Gunnell, B Galobardes, P McCarron
}

Thorax 2006;61:48-53. doi: 10.1136/thx.2004.034595

See end of article for authors' affiliations



Correspondence to: Dr S Kinra, Canynge Hall, Whiteladies Road, Bristol BS8 2PR, UK; Sanjay.
Kinra@bristol.ac.uk

Received 9 September 2004

Accepted 16 April 2005
Background: Recent epidemiological studies consistently report an inverse association between sibship size and allergic disease, but evidence from individuals born before the 1980s is inconsistent. As information on relative permanence of this finding may offer clues to its biological explanation, the association between sibship size and allergic disease in individuals born between 1918 and 1952 was investigated.

Methods: Cross sectional surveys conducted by the Student Health Service at the University of Glasgow (1948-68) provided data on 14140 men and women aged 16-30 years at the time of examination. The main outcome measures studied were self-reported asthma, eczema-urticaria, and hay fever.

Results: A total of 1677 individuals (11.9\%) provided a positive history of at least one of the three allergic diseases: 457 (3.2\%) asthma, 594 (4.2\%) eczema-urticaria, and 885 (6.3\%) hay fever. Compared with those without siblings (reference odds ratio $=1)$, the odds ratios $(95 \%$ confidence intervals) for having any allergic disease among those with one, two or three siblings were 0.86 (0.75 to 0.99$), 0.80$ (0.69 to 0.93 ), and $0.70(0.60$ to 0.83$)$, respectively ( $\left.p_{\text {trend }}<0.001\right)$. Increasing birth order and low socioeconomic position in childhood were associated with a lower risk of allergy. Adjustment for birth order, year of birth, age, sex, socioeconomic position in childhood, and family history of allergy did not materially alter the results.

Conclusions: There is a robust inverse association between sibship size and allergic disease even among people born in the first half of the 20th century. These results favour relatively time-independent explanations for this phenomenon (such as the hygiene hypothesis or parity related changes in the intrauterine environment) over new environmental exposures.
$\mathrm{R}$ ecent epidemiological studies consistently show an inverse association between sibship size and allergic disease, but there is no biological explanation for this empirical observation. ${ }^{1-5}$ It has been estimated that up to a third of cases with allergy could be accounted for by this socalled sibling effect. ${ }^{5}$

Strachan formulated the "hygiene hypothesis" in 1989, suggesting that the risk of allergic diseases is reduced by infections in infancy transmitted by older siblings. ${ }^{6}$ Despite immunological plausibility, the causal role of infections in allergic diseases remains unproven as data from studies that have used more direct markers of infection have been inconclusive..$^{5-10}$ Furthermore, epidemiological data supportive of a sibling effect in individuals born before the 1980s are limited and inconsistent. ${ }^{11-15}$ If infections are the underlying protective factor, one would predict the sibling effect to be stronger-not weaker-at a time when the hygiene differentials are potentially steeper. Consequently, alternative explanations for the sibling effect have been proposed that mainly relate to inherent differences in immune function (the "intrauterine programming hypothesis"). ${ }^{5}$ Birth order may affect the fetal atopic response directly or indirectly through induction of immune tolerance in the mother. ${ }^{16-20}$ Other mechanisms suggested to explain intrauterine programming include a potential role for hormones as well as endocrine disrupters such as organochlorines. $^{521-23}$

We have investigated the association between sibship size and the prevalence of allergic diseases in a historical cohort who were born in the first half of the 20th century. We hypothesised that a robust documentation of the sibling effect in this early cohort would lend support to relatively time-independent explanations offered by the hygiene hypothesis or inherent birth order related differences in immunity over new exposures such as organochlorines.

\section{METHODS}

The Glasgow Alumni Study has been described in detail elsewhere. ${ }^{24}$ Briefly, students who were registered at the University of Glasgow sometime between 1948 and 1968 were invited to an annual medical examination at the Student Health Service. Approximately 50\% of the students attended. Substantial sociodemographic and medical data were collected through a physician administered questionnaire. Students provided information on their birth order, number of siblings, father's occupation, and whether they had ever suffered any of the four allergic diseases: asthma, eczema, urticaria, or hay fever. Students were also asked to report if any of their first degree relatives (parents or siblings) suffered from one of the aforementioned allergic diseases.

Ethics committee approval was received for the study.

\section{Statistical analysis}

Logistic regression modelling was performed to examine the association between sibship size, birth order or childhood socioeconomic position and risk of having allergic disease. Eczema and urticaria were combined into one outcome to limit diagnostic misclassification between them. Associations were investigated with each of the three allergic disease outcomes-asthma, eczema-urticaria and hay fever-and also for the combined outcome-allergy_defined as having any of these diseases.

Analysis was restricted to students who underwent examination when they were 30 years or younger as the few older students $(\mathrm{N}=546)$ were spread over a wide age range. Age at examination was calculated as the difference 
between date of examination and date of birth, and divided into three groups (in completed years) for analysis (16-19, 20-24, and 25-29). The sibship size was categorised into four groups $(0,1,2$, and $3+)$ and birth order into three categories ( 1 (first born), 2, 3+). Childhood socioeconomic position was determined from the occupation of the father using the Registrar General's classification (I-IV); social classes IV and $\mathrm{V}$ were combined because of low numbers in these two categories. Year of birth was divided into three time periods (1918-30, 1931-39, and 1940-52) to study birth cohort effects. Family history of allergy was examined as a combined variable for any first degree relatives suffering from any of the three allergic diseases, as there were low numbers in each of the groups individually.

The main exposures considered in the analyses were sibship size and birth order, along with childhood socioeconomic position which was important because of its relevance to the hygiene hypothesis. Crude models were first adjusted for age, year of birth, and the year of student examination to investigate possible confounding by age of the participant, or change over time of disease prevalence or definitions. In subsequent models we controlled for sex and family history of allergy. The final model contained terms for sibship size, birth order, childhood socioeconomic position, age, sex, year of birth, year of student examination, and family history of allergy. We also specifically looked for evidence of any important interactions between sibship size and birth order, and between either of these two with childhood socioeconomic position, period of birth, age, sex, and family history of allergy. To study the change over time, we fitted the above models independently for each of the three birth cohort periods and also calculated the age-sex standardised prevalence for each of the diseases. Direct standardisation was done using the age-sex distribution of the entire cohort as the reference.

\section{RESULTS}

The Glasgow Alumni cohort consists of 15322 former students of whom $11755(77 \%)$ are men. After excluding students over the age of 30 years $(n=546)$, those with unknown year of birth $(\mathrm{n}=2)$ and those with missing data on sibling number or birth order $(n=169)$ and father's occupation $(n=465)$, complete data were available on 14140 individuals $(92 \%), 10732(76 \%)$ of whom were men. The students were born between 1918 and 1952 and their median age at the time of university medical examinations was 19.4 years (range 16-30).

A total of 1677 individuals (11.9\%) provided a positive history of at least one of the three allergic diseases: 457 (3.2\%) asthma, 594 (4.2\%) eczema-urticaria, and 885 (6.3\%) hay fever. A further 1404 (9.9\%) reported having at least one first degree relative who suffered from any one of these diseases (table 1). After standardising for age-sex distribution, the prevalence for each of these diseases across the birth cohort categories was very similar (data not presented). For any allergy, the standardised prevalence (95\% confidence interval (CI)) was $12.2 \%$ ( 10.5 to 13.9 ), $12.0 \%$ (11 to 12.9 ), and $11.7 \%$ (10.6 to 12.9 ) for birth periods 1918-29, 1930-39, and 1940-52, respectively.

The odds ratios for having at least one allergic disease decreased with increasing number of siblings, with individuals who had three or more siblings having a 30\% lower risk of being affected than those without siblings (table 2). A similar effect size and trend was noted with increasing birth order. Individuals from the least affluent backgrounds had the lowest risk of allergic disease. Adjustment for year of birth, year of examination, age, sex, and family history of allergic disease and further adjustment, as appropriate, for sibship size, birth order and childhood socioeconomic position did not materially alter these findings. Among the allergic diseases, hay fever showed the strongest association and asthma the weakest association with sibship size.

\begin{tabular}{|c|c|c|c|c|c|c|c|c|c|}
\hline & \multirow{2}{*}{$\frac{\text { Participants }}{\%(\mathrm{~N})}$} & \multicolumn{2}{|l|}{ Asthma } & \multicolumn{2}{|c|}{ Eczema-urticaria } & \multicolumn{2}{|l|}{ Hay fever } & \multicolumn{2}{|l|}{ Allergy* } \\
\hline & & $\%(\mathrm{~N})$ & Ptrend & $\%(\mathrm{~N})$ & Ptrend & $\%(\mathrm{~N})$ & Ptrend & $\%(\mathbf{N})$ & Ptrend \\
\hline \multicolumn{10}{|c|}{ Age at university examination } \\
\hline $16-19$ & $59.3(8386)$ & $3.3(277)$ & \multirow[t]{3}{*}{0.158} & $4.0(332)$ & \multirow[t]{3}{*}{0.072} & $6.6(549)$ & \multirow[t]{3}{*}{0.001} & $12.1(1012)$ & \multirow[t]{3}{*}{0.159} \\
\hline $20-24$ & $33.4(4717)$ & $3.3(157)$ & & $4.4(206)$ & & $6.3(299)$ & & $11.9(561)$ & \\
\hline $25-29$ & $7.3(1037)$ & $2.2(23)$ & & $5.4(56)$ & & $3.6(37)$ & & $10.0(104)$ & \\
\hline \multicolumn{10}{|l|}{ Sex } \\
\hline Male & 75.9 (10732) & $3.6(382)$ & \multirow[t]{3}{*}{$<0.001$} & $3.6(382)$ & \multirow[t]{3}{*}{$<0.001$} & $6.1(655)$ & \multirow[t]{3}{*}{0.175} & $11.4(1223)$ & \multirow[t]{3}{*}{0.002} \\
\hline Female & $24.1(3408)$ & $2.2(75)$ & & $6.2(212)$ & & $6.8(230)$ & & $13.3(454)$ & \\
\hline \multicolumn{6}{|l|}{ Sibship size } & & & & \\
\hline 0 & $18.6(2634)$ & $2.5(91)$ & \multirow[t]{4}{*}{0.333} & $4.7(123)$ & \multirow[t]{4}{*}{0.024} & $7.9(207)$ & \multirow{4}{*}{$<0.001$} & $13.8(364)$ & \multirow{4}{*}{$<0.001$} \\
\hline 1 & $36.8(5197)$ & $3.3(169)$ & & $4.6(238)$ & & $6.4(330)$ & & $12.2(633)$ & \\
\hline 2 & 23.6 (3339) & $3.3(109)$ & & $3.6(119)$ & & $6.1(203)$ & & $11.4(379)$ & \\
\hline $3+$ & $21.0(2970)$ & $3.0(88)$ & & 3.8 (114) & & $4.9(145)$ & & $10.1(301)$ & \\
\hline \multicolumn{10}{|l|}{ Birth order } \\
\hline 1 & $55.8(7885)$ & $3.6(281)$ & \multirow[t]{3}{*}{0.007} & 4.3 (338) & \multirow[t]{3}{*}{0.247} & $7.0(550)$ & \multirow[t]{3}{*}{$<0.001$} & $12.7(1002)$ & \multirow[t]{3}{*}{$<0.001$} \\
\hline 2 & 26.7 (3769) & $3.0(113)$ & & $4.4(166)$ & & $5.9(222)$ & & $11.7(439)$ & \\
\hline $3+$ & $17.6(2486)$ & $2.5(63)$ & & $3.6(90)$ & & $4.6(113)$ & & $9.5(236)$ & \\
\hline \multicolumn{10}{|c|}{ Childhood socioeconomic position } \\
\hline 1 & $20.9(2952)$ & $3.5(104)$ & \multirow{4}{*}{0.571} & $5.0(148)$ & \multirow{4}{*}{0.006} & $7.8(230)$ & \multirow{4}{*}{$<0.001$} & $13.7(404)$ & $<0.001$ \\
\hline ॥ & $36.8(5200)$ & $3.0(158)$ & & $4.2(220)$ & & $6.9(356)$ & & $12.1(628)$ & \\
\hline III & 35.7 (5053) & $3.3(168)$ & & 3.8 (194) & & $5.1(257)$ & & $11.0(556)$ & \\
\hline IV-V & $6.6(935)$ & $2.9(27)$ & & $3.4(32)$ & & $4.5(42)$ & & $9.5(89)$ & \\
\hline Period of bir & & & & & & & & & \\
\hline $1918-30$ & 24.9 (3518) & $2.7(96)$ & 0.896 & $4.8(169)$ & 0.011 & $5.2(183)$ & 0.005 & 11.1 (392) & 0.638 \\
\hline $1931-39$ & $37.8(5345)$ & 3.6 (194) & & 4.2 (222) & & 6.4 (344) & & $12.2(650)$ & \\
\hline $1940-52$ & 37.3 (5277) & $3.2(167)$ & & $3.9(203)$ & & 6.8 (358) & & $12.0(635)$ & \\
\hline Family histor & & & & & & & & & \\
\hline & 90.1 (12736) & 2.7 (349) & $<0.001$ & $3.7(467)$ & $<0.001$ & $5.3(670)$ & $<0.001$ & $10.3(1305)$ & $<0.001$ \\
\hline Yes & $9.9(1404)$ & 7.7 (108) & & 9.1 (127) & & $15.3(215)$ & & $26.5(372)$ & \\
\hline
\end{tabular}

*Allergy refers to the participant reporting any of the three diseases (asthma, eczema-urticaria, or hay fever). 
Table 2 Association of combined allergic diseases, asthma, eczema-urticaria and hay fever with sibship size, birth order and childhood socio-economic position

\begin{tabular}{|c|c|c|c|c|c|c|c|c|c|}
\hline & \multicolumn{3}{|c|}{ Crude } & \multicolumn{3}{|c|}{ Partially adjusted* } & \multicolumn{3}{|c|}{ Fully adjusted† } \\
\hline & $\overline{O R}$ & $95 \% \mathrm{Cl}$ & Ptrend & OR & $95 \% \mathrm{Cl}$ & Ptrend & $\overline{O R}$ & $95 \% \mathrm{Cl}$ & Ptrend \\
\hline \multicolumn{10}{|c|}{ Eczema-urticaria } \\
\hline 0 & 1 & & & 1 & & & 1 & & \\
\hline 1 & 0.98 & (0.78 to 1.22$)$ & & 0.94 & (0.75 to 1.17 ) & & 0.89 & (0.70 to 1.14 ) & \\
\hline 2 & 0.75 & (0.58 to 0.98 ) & & 0.71 & $(0.55$ to 0.92$)$ & & 0.67 & $(0.50$ to 0.90$)$ & \\
\hline $3+$ & 0.81 & (0.63 to 1.06 ) & 0.024 & 0.73 & $(0.56$ to 0.96$)$ & 0.003 & 0.71 & (0.52 to 0.97 ) & 0.007 \\
\hline \multicolumn{10}{|c|}{ Birth order } \\
\hline 1 & 1 & & & 1 & & & 1 & & \\
\hline 2 & 1.03 & (0.85 to 1.24 ) & & 1.02 & (0.84 to 1.23 ) & & 1.10 & (0.89 to 1.36 ) & \\
\hline $3+$ & 0.84 & (0.66 to 1.06 ) & 0.247 & 0.82 & (0.64 to 1.04 ) & 0.178 & 1.03 & (0.77 to 1.38 ) & 0.658 \\
\hline \multicolumn{10}{|c|}{$\begin{array}{l}\text { Childhood } \\
\text { socioeconomic position }\end{array}$} \\
\hline 1 & 1 & & & 1 & & & 1 & & \\
\hline ॥ & 0.84 & (0.68 to 1.04 ) & & 0.84 & (0.68 to 1.05 ) & & 0.84 & (0.68 to 1.04$)$ & \\
\hline III & 0.76 & $(0.61$ to 0.94$)$ & & 0.80 & $(0.64$ to 1.00$)$ & & 0.80 & (0.64 to 1.00$)$ & \\
\hline IV-V & 0.67 & (0.46 to 0.99 ) & 0.006 & 0.75 & $(0.51$ to 1.11$)$ & 0.045 & 0.77 & $(0.52$ to 1.14$)$ & 0.054 \\
\hline \multicolumn{10}{|c|}{ Hay fever } \\
\hline \multicolumn{10}{|c|}{ Sibship size } \\
\hline 0 & 1 & & & 1 & & & 1 & & \\
\hline 1 & 0.79 & $(0.66$ to 0.95$)$ & & 0.74 & (0.62 to 0.89 ) & & 0.76 & (0.62 to 0.92$)$ & \\
\hline 2 & 0.76 & (0.62 to 0.93 ) & & 0.68 & (0.55 to 0.83 ) & & 0.73 & $(0.59$ to 0.92$)$ & \\
\hline $3+$ & 0.60 & (0.48 to 0.75 ) & $<0.001$ & 0.55 & $(0.44$ to 0.68$)$ & $<0.001$ & 0.63 & $(0.49$ to 0.82$)$ & 0.001 \\
\hline \multicolumn{10}{|c|}{ Birth order } \\
\hline 1 & 1 & & & 1 & & & 1 & & \\
\hline 2 & 0.83 & $(0.71$ to 0.98$)$ & & 0.82 & $(0.70$ to 0.96$)$ & & 0.91 & $(0.76$ to 1.08$)$ & \\
\hline $3+$ & 0.64 & (0.52 to 0.78 ) & $<0.001$ & 0.63 & $(0.51$ to 0.77$)$ & $<0.001$ & 0.78 & $(0.61$ to 1.00$)$ & 0.041 \\
\hline \multicolumn{10}{|c|}{$\begin{array}{l}\text { Childhood } \\
\text { socioeconomic position }\end{array}$} \\
\hline 1 & 1 & & & 1 & & & 1 & & \\
\hline ॥I & 0.87 & (0.73 to 1.03 ) & & 0.88 & (0.74 to 1.05 ) & & 0.89 & $(0.74$ to 1.06$)$ & \\
\hline III & 0.63 & $(0.53$ to 0.76$)$ & & 0.65 & $(0.54$ to 0.78$)$ & & 0.65 & (0.54 to 0.79 ) & \\
\hline IV-V & 0.56 & (0.40 to 0.78 ) & $<0.001$ & 0.59 & $(0.42$ to 0.83$)$ & $<0.001$ & 0.61 & $(0.44$ to 0.86$)$ & $<0.001$ \\
\hline
\end{tabular}

OR, odds ratio; $95 \% \mathrm{Cl}, 95 \%$ confidence intervals.

*Adjusted for age, sex, year of birth, year of examination, and family history of allergy.

†Adjusted for sibship size, birth order, childhood socioeconomic position, age, sex, year of birth, year of examination, and family history of allergy.

The association between sibship size or birth order and the risk of allergic disease was at least as strong, if not stronger, in the earlier birth cohort period as in the later ones (table 3 ). Similar patterns were noted for each of the individual diseases (data not presented). Most of the interactions outlined in the Methods section were non-contributory. However, an important interaction was noted between birth order and childhood socioeconomic position, such that the risk of allergic disease in those with birth order three or higher and belonging to the lowest socioeconomic group was less than a third that of individuals with birth order one and belonging to the highest socioeconomic group (table 4). We did not find a similar interaction between sibship size and allergic disease.

\section{DISCUSSION}

This study has shown that the inverse association between sibship size or birth order and risk of allergic diseases was evident even in the first half of the 20th century. The association was at least as strong, if not stronger, in the earlier birth cohort period (1918-30) as in the later ones. Lower socioeconomic position in childhood was associated with lower odds of allergic disease. These associations were robust to adjustments for each other and other potential confounders including year of birth or examination, age, sex, and family history of allergic disease. The protective effect of higher birth order to allergy was strongest in the poorest households.

\section{Strengths and limitations of the study}

Participants were asked to provide a history of allergic diseases. Although physicians collected the data, we are not aware if any clear diagnostic criteria were established beforehand, and this may have introduced measurement error in the outcome. Such error, if present, is likely to be non-differential and so would have acted only to reduce the strength of the true association. Diagnostic criteria can also change over time; however, we are not aware of any major changes in diagnosis of allergic diseases over the study period (1948-68). No significant changes were noted in the prevalence of these diseases over the duration of the study, nor were there any important interactions between year of examination, year of birth, and sibship size or birth order.

Apart from the large sample size and its unique historical timing (before antibiotics and immunisation came into widespread use), another important strength of this study is the availability of family history data. There is some evidence to suggest that allergic predisposition may be related to fertility; if true, maternal history of allergy may confound the association between sibship size and allergic disease among the offspring. ${ }^{25}{ }^{26}$ Unlike most previous studies which did not have these data, we were able to control for family history of disease. ${ }^{5}$

\section{Comparison of results with other studies}

There are few large scale epidemiological studies with data available from a similar time period with which to compare the prevalence of these diseases. As expected, the prevalence found in this study was lower than that reported in recent studies such as the ISAAC. ${ }^{27}$ The Midspan 1972-76 study of parents and their offspring from two towns in the west of Scotland reported age standardised prevalence of $5.4-5.8 \%$ for hay fever and $1.4-2.8 \%$ for asthma among parents aged 
Table 3 Association of sibship size and birth order with prevalence of allergy by three periods of birth

\begin{tabular}{|c|c|c|c|c|c|c|c|c|c|}
\hline & \multicolumn{3}{|c|}{ Crude } & \multicolumn{3}{|c|}{ Partially adjusted* } & \multicolumn{3}{|c|}{ Fully adjusted $†$} \\
\hline & $\overline{\mathrm{OR}}$ & $95 \% \mathrm{Cl}$ & Ptrend & $\overline{\mathrm{OR}}$ & $95 \% \mathrm{Cl}$ & Pirend & $\overline{\mathrm{OR}}$ & $95 \% \mathrm{Cl}$ & Ptrend \\
\hline \multicolumn{10}{|c|}{ Born 1918-1930 } \\
\hline \multicolumn{10}{|c|}{ Sibship size } \\
\hline 0 & 1 & & & 1 & & & 1 & & \\
\hline 1 & 0.75 & (0.56 to 0.99$)$ & & 0.72 & (0.54 to 0.96$)$ & & 0.76 & (0.56 to 1.02$)$ & \\
\hline 2 & 0.59 & (0.43 to 0.82 ) & & 0.58 & $(0.42$ to 0.80$)$ & & 0.64 & $(0.45$ to 0.93$)$ & \\
\hline $3+$ & 0.52 & (0.38 to 0.72 ) & $<0.001$ & 0.49 & $(0.35$ to 0.67$)$ & $<0.001$ & 0.57 & $(0.38$ to 0.85$)$ & 0.006 \\
\hline \multicolumn{10}{|c|}{ Birth order } \\
\hline 1 & 1 & & & 1 & & & 1 & & \\
\hline 2 & 0.67 & (0.52 to 0.86$)$ & & 0.68 & (0.52 to 0.87$)$ & & 0.76 & (0.58 to 1.00$)$ & \\
\hline $3+$ & 0.63 & (0.47 to 0.83 ) & $<0.001$ & 0.62 & (0.47 to 0.83 ) & $<0.001$ & 0.87 & (0.60 to 1.25 ) & 0.202 \\
\hline \multicolumn{10}{|c|}{ Born 1931-1939 } \\
\hline \multicolumn{10}{|c|}{ Sibship size } \\
\hline 0 & 1 & & & 1 & & & 1 & & \\
\hline 1 & 0.92 & (0.74 to 1.14 ) & & 0.84 & (0.67 to 1.04 ) & & 0.86 & (0.68 to 1.07 ) & \\
\hline 2 & 0.85 & (0.67 to 1.09 ) & & 0.76 & $(0.59$ to 0.98$)$ & & 0.80 & (0.61 to 1.05 ) & \\
\hline \multirow{2}{*}{\multicolumn{10}{|c|}{$0.17 \quad(0.5 /$ to 1.05$)$}} \\
\hline & & & & & & & & & \\
\hline 1 & 1 & & & 1 & & & 1 & & \\
\hline 2 & 1.00 & (0.82 to 1.21$)$ & & 0.92 & (0.76 to 1.12$)$ & & 0.96 & (0.78 to 1.18 ) & \\
\hline $3+$ & 0.74 & (0.58 to 0.95 ) & 0.039 & 0.71 & (0.55 to 0.91$)$ & 0.178 & 0.83 & (0.62 to 1.12 ) & 0.262 \\
\hline \multicolumn{10}{|c|}{ Born 1940-1952 } \\
\hline \multicolumn{10}{|c|}{ Sibship size } \\
\hline 0 & 1 & & & 1 & & & 1 & & \\
\hline 1 & 0.90 & (0.71 to 1.13 ) & & 0.85 & (0.67 to 1.08$)$ & & 0.86 & (0.67 to 1.10$)$ & \\
\hline 2 & 0.89 & (0.69 to 1.15 ) & & 0.80 & (0.62 to 1.03 ) & & 0.82 & (0.62 to 1.09 ) & \\
\hline $3+$ & 0.79 & (0.60 to 1.05 ) & 0.129 & 0.70 & (0.53 to 0.93 ) & 0.067 & 0.74 & (0.54 to 1.01 ) & 0.066 \\
\hline \multicolumn{10}{|c|}{ Birth order } \\
\hline 1 & 1 & & & 1 & & & 1 & & \\
\hline 2 & 1.00 & (0.82 to 1.20$)$ & & 0.98 & (0.81 to 1.19$)$ & & 1.03 & (0.84 to 1.25 ) & \\
\hline $3+$ & 0.78 & (0.60 to 1.01 ) & 0.106 & 0.76 & $(0.58$ to 0.98$)$ & 0.178 & 0.86 & (0.64 to 1.16 ) & 0.488 \\
\hline
\end{tabular}

OR, odds ratio; $95 \% \mathrm{Cl}, 95 \%$ confidence intervals.

*Adjusted for age, sex, year of birth, year of examination, and family history of allergy.

†Adjusted for sibship size, birth order, childhood socioeconomic position, age, sex, year of birth, year of examination, and family history of allergy. Interaction tests for fully adjusted models: (a) sibship size and period of birth, $p=0.554$; (b) birth order and period of birth, $p=0.209$.

45-54 years at the time. ${ }^{28}$ Both these figures, which were selfreported, are comparable to the data in our study $(6.3 \%$ for hay fever and $3.2 \%$ for asthma), as are the setting and the timing, since the participants were born between 1918 and 1931. The offspring survey in the same study indicated that there had been a doubling of the prevalence over a 20 year period. ${ }^{28}$

Recent epidemiological studies have reported similar associations between sibship size, birth order or socioeconomic position, and allergic diseases. ${ }^{1-5}$ Most of these studies, however, were conducted over the last two decades while those from before that time have generally been small and inconsistent in their findings. ${ }^{11-15}$ Smaller and often casebased studies have reported similar associations. ${ }^{11}{ }^{12}$ On the other hand, large scale epidemiological studies based on unselected samples from the general population born before the 1980s have often failed to reproduce these results. ${ }^{13-15}$ One plausible explanation for the inconsistency in results could be related to the choice of asthma as the outcome, since the sibling effect has generally been observed to be weaker for asthma than for other allergic diseases and the same was true in our study. ${ }^{5}$ It is unclear whether the relatively weaker associations reported with asthma represent diagnostic difficulties or differences in disease aetiology, as not all asthma is allergic in origin. ${ }^{29}$

\section{Competing hypotheses that seek to explain the sibling effect}

If the sibling effect has existed unchanged for some time, then the most parsimonious explanations would have to be time-independent. For this, two categories of hypotheses exist. ${ }^{5}$ The first, and by far the most popular, is the hygiene hypothesis. ${ }^{6}$ The hygiene hypothesis predicts that the sibling effect would be as strong, if not stronger, in the earlier cohorts (due to greater differentials in hygiene) and among the less affluent (due to greater potential for infections). Both these predictions held true in our study. In addition, we found an interaction between birth order and socioeconomic

Table 4 Odds ratios $(95 \% \mathrm{Cl})$ for prevalence of allergy by birth order and childhood socioeconomic position

\begin{tabular}{llll}
\hline $\begin{array}{l}\text { Childhood } \\
\text { socioeconomic } \\
\text { position }\end{array}$ & \multicolumn{2}{l}{ Birth order } & $3+$ \\
\cline { 2 - 4 } & $\mathbf{1}$ & $\mathbf{2}$ & $\mathbf{3}$ \\
\hline I & 1 & $1.00(0.79$ to 1.28$)$ & $1.01(0.74$ to 1.37$)$ \\
II & 1 & $0.91(0.75$ to 1.11$)$ & $0.58(0.44$ to 0.75$)$ \\
III & 1 & $0.84(0.68$ to 1.04$)$ & $0.84(0.66$ to 1.07$)$ \\
IV-V & 1 & $0.80(0.48$ to 1.33$)$ & $0.36(0.18$ to 0.71$)$ \\
\hline
\end{tabular}

Test for interaction between birth order and childhood socioeconomic position, $p=0.035$ 
position which would further support the hygiene hypothesis. Spread of infections within large families would be more likely in households from lower socioeconomic position due to overcrowding (and possibly poorer personal hygiene) than in more affluent households. This interaction was not prespecified, however, nor was it seen for sibship size, so it could be a chance finding.

Despite a plausible immunological basis (repeated infections leading to the induction of Thl pattern of cytokine in turn suppressing the Th2 responses involved in immunoglobin $\mathrm{E}$ (IgE) mediated allergy), the causal role of infections in allergic diseases remains unproven as data from studies that have used more direct markers of infection have been inconclusive. $^{57-10}$ This failure may be attributable, at least in part, to difficulties involved in measuring these exposures accurately and should not be taken as strong evidence against it. It is noteworthy that several of these studies regarded levels of antibiotic usage and vaccination status as proxies for frequency of early infections, while most of the participants in our study were born before their widespread introduction. ${ }^{57}$ Establishing a relationship with infections is important as reduced family size by itself cannot account for the dramatic rise in the prevalence of allergic conditions seen over the last century. ${ }^{30}$

Others argue that the inverse association between childhood infections and risk of allergy is not causal but a manifestation of the same underlying defect. The "in utero programming disruption hypothesis" suggests that parity related changes in the intrauterine environment result in differing programming of Th1/Th2 responses in the developing fetus which influences both the risk of infections and allergy in childhood. ${ }^{5}$ The view that the sibling effect is established at birth is supported by studies that show lower levels of cord blood IgE (or T helper cell responses) with higher birth order; the cord blood IgE levels have been shown to be related to later risk of allergy. ${ }^{16-18}$ It is unclear whether birth order affects the atopic response in the fetus directly, or indirectly through induction of immune tolerance in the mother which is transmitted to subsequent offspring (tolerance induction and transmission hypotheses). ${ }^{19} 20$ Other mechanisms suggested to explain intrauterine programming include a potential role for hormones (progesterone and testosterone promote preferential development of Th2 type cells) as well as endocrine disrupters such as organochlorines that can alter the levels of these hormones. ${ }^{51-23}$ The burden of organochlorines has been shown to decrease with birth order and to be associated with higher cord blood IgE levels. ${ }^{22}{ }^{23}$ However, in the current study the robust documentation of the sibling effect from a time before organochlorines came into widespread use, in addition to a reported decline in the use of organochlorines in some countries, argues against an important aetiological role for these compounds. ${ }^{31}$

Few studies have tried to assess the independent effects of sibship size and birth order on the prevalence of allergy. Some,

\section{Box 1 Key findings}

- The inverse association between sibship size and allergic disease was evident even in individuals born between 1918 and 1952.

- Social class did not confound this association.

- There was no clear evidence for an increase in the prevalence of allergy between 1918 and 1952.

- This favours the relatively time-independent explanations for the sibling effect (such as the hygiene hypothesis or parity related changes in the intrauterine environment) over new environmental exposures. but not all, have been able to demonstrate independent effects. ${ }^{1-4}{ }^{6}$ The likely explanation for this is the difference in the power of these studies. Birth order and sibship size are moderately correlated (in our study $r=0.55$ for truncated forms of these variables used in the analyses and $r=0.63$ for full range of the variables), thereby requiring large sample sizes to manifest independent effects. Studies that have shown independent effects of birth order (or the number of older siblings) and sibship size (or the number of younger siblings) generally had larger sample sizes (often in excess of 10000 participants $)^{126}$ than "negative" studies which had wide overlapping confidence intervals for these variables. ${ }^{3}{ }^{4}$ The finding of independent effects of sibship size and birth order is important as the two may represent different underlying mechanisms. While a sibling effect, independent of birth order, would be more supportive of postnatal influences such as early childhood infections (that is, the hygiene hypothesis), a birth order effect, independent of sibling number, would suggest a predominantly prenatal mechanism (that is, intrauterine programming). Equally, a common underlying exposure operating across both the intrauterine and postnatal periods may give rise to these findings.

\section{Public health implications}

Epidemiological data suggest a steady rise in the prevalence of allergic disease over the last century but more so in the last two or three decades. ${ }^{32}$ The reasons for this are unknown. It has been suggested that the same unknown environmental factor(s) may underlie both the rise in the prevalence of these conditions globally and the inverse association between the risk of these conditions and sibship size noted at an individual level. ${ }^{57}$ It has been suggested that up to a third of cases with allergy could be accounted for by the sibling effect. Knowledge of factors underlying the sibling effect may help to prevent some of these cases.

In conclusion, this study has shown that the inverse association between sibship size and allergic disease was evident even in the first half of the last century. The finding of the sibling effect in this early cohort argues against an important role for new environmental exposures in favour of relatively time-independent explanations offered by the hygiene hypothesis or parity related changes in the intrauterine environment. The key findings of this study are shown in box 1 .

\section{Authors' affiliations}

S Kinra, G Davey Smith, D Gunnell, B Galobardes, Department of Social Medicine, University of Bristol, Bristol, UK

M Jeffreys, Centre for Public Health Research, Massey University, Wellington, New Zealand

P McCarron, Department of Epidemiology and Public Health, The Queen's University of Belfast, Belfast, UK

This study was funded by the Stroke Association, Chest Heart and Stroke, Scotland, NHS R\&D CVD Programme, and the World Cancer Research Fund. PMCC is supported by a career scientist award funded by the Research \& Development Office for Health and Personal Social Services in Northern Ireland. The Centre for Public Health Research is supported by a Programme Grant from the Health Research Council of New Zealand.

Competing interests: none.

GDS had the original idea for the study. SK analysed the data and wrote the first draft of the paper. All authors contributed to the final manuscript. SK is the guarantor.

\section{REFERENCES}

1 Strachan DP, Taylor EM, Carpenter RG. Family structure, neonatal infection, and hay fever in adolescence. Arch Dis Child 1996:74:422-6.

2 Matricardi PM, Franzinelli F, Franco A, et al. Sibship size, birth order, and atopy in 11,371 Italian young men. J Allergy Clin Immunol 1998;101:439-44. 
3 Jarvis D, Chinn S, Luczynska C, et al. The association of family size with atopy and atopic disease. Clin Exp Allergy 1997;27:240-5.

4 Bernsen RM, de Jongste JC, van der Wouden JC. Birth order and sibship size as independent risk factors for asthma, allergy, and eczema. Pediatr Allergy Immunol 2003; 14:464-9.

5 Karmaus W, Botezan C. Does a higher number of siblings protect against the development of allergy and asthma? A review. J Epidemiol Community Health 2002;56:209-17.

6 Strachan DP. Hay fever, hygiene, and household size. BMJ 1989;299:1259-60.

7 Strachan DP. Family size, infection and atopy: the first decade of the "hygiene hypothesis". Thorax 2000;55(Suppl 1):S2-10.

8 Benn CS, Melbye M, Wohlfahrt J, et al. Cohort study of sibling effect, infectious disease, and risk of atopic dermatitis during first 18 months of life. BMJ 2004;328:1223-6.

9 Matricardi PM, Rosmini F, Riondino S, et al. Exposure to foodborne and orofecal microbes versus airborne viruses in relation to atopy and allergic asthma: epidemiological study. BMJ 2000;320:412-7.

10 Matricardi PM, Rosmini F, Panetta V, et al. Hay fever and asthma in relation to markers of infection in the United States. J Allergy Clin Immunol 2002;110:381-7.

11 Chen E, Cobb S. Family structure in relation to health and disease: a review of the literature. J Chronic Dis 1960; 12:544-67.

12 Dawson B, Horobin G, Illsley R, et al. A survey of childhood asthma in Aberdeen. Lancet 1969;1:827-30.

13 Peckham C, Butler N. A national study of asthma in childhood. J Epidemiol Community Health 1978;32:79-85.

14 Rona RJ, Hughes JM, Chinn S. Association between asthma and family size between 1977 and 1994. J Epidemiol Community Health 1999:53:15-9.

15 Hamman RF, Halil T, Holland WW. Asthma in schoolchildren. Demographic associations and peak expiratory flow rates compared in children with bronchitis. Br J Prev Soc Med 1975;29:228-38.

16 Karmaus W, Arshad H, Mattes J. Does the sibling effect have its origin in utero? Investigating birth order, cord blood immunoglobulin E concentration, and allergic sensitization at age 4 years. Am J Epidemiol 2001;154:909-15.

17 Devereux G, Barker RN, Seaton A. Antenatal determinants of neonatal immune responses to allergens. Clin Exp Allergy 2002;32:43-50.
18 van Gool CJ, Thiis $C$, Dagnelie PC, et al. Determinants of neonatal lgE level: parity, maternal age, birth season and perinatal essential fatty acid status in infants of atopic mothers. Allergy 2004;59:961-8.

19 Karmaus W, Arshad SH, Sadeghnejad A, et al. Does maternal immunoglobulin E decrease with increasing order of live offspring? Investigation into maternal immune tolerance. Clin Exp Allergy 2004;34:853-9.

20 Harris JM, White C, Moffat S, et al. New pregnancies and loss of allergy. Clin Exp Allergy 2004;34:369-72.

21 Whitacre CC, Reingold SC, O'Looney PA. A gender gap in autoimmunity. Science 1999;283:1277-8.

22 Vaz R, Slorach SA, Hofvander Y. Organochlorine contaminants in Swedish human milk: studies conducted at the National Food Administration 19811990. Food Addit Contam 1993;10:407-18.

23 Reichrtova $\mathrm{E}$, Ciznar $\mathrm{P}$, Prachar $\mathrm{V}$, et al. Cord serum immunoglobulin $\mathrm{E}$ related to the environmental contamination of human placentas with organochlorine compounds. Environ Health Perspect 1999;107:895-9.

24 McCarron P, Smith GD, Okasha M, et al. Life course exposure and later disease: a follow-up study based on medical examinations carried out in Glasgow University (1948-68). Public Health 1999;113:265-71.

25 Sunyer J, Anto JM, Harris J, et al. Maternal atopy and parity. Clin Exp Allergy 2001;31:1352-5.

26 Doull IJ. Does pregnancy prevent atopy? Clin Exp Allergy 2001;31:1335-7.

27 Austin JB Kaur B, Anderson HR, et al. Hay fever, eczema, and wheeze: a nationwide UK study (ISAAC, International Study of Asthma and Allergies in Childhood). Arch Dis Child 1999;81:225-30.

28 Upton MN, McConnachie A, McSharry C, et al. Intergenerational 20 year trends in the prevalence of asthma and hay fever in adults: the Midspan family study surveys of parents and offspring. BMJ 2000;321:88-92.

29 Pearce N, Pekkanen J, Beasley R. How much asthma is really attributable to atopy? Thorax 1999;54:268-72.

30 Wickens K, Crane J, Pearce N, et al. The magnitude of the effect of smaller family sizes on the increase in the prevalence of asthma and hay fever in the United Kingdom and New Zealand. J Allergy Clin Immunol 1999;104:554-8.

31 Key T, Reeves $G$. Organochlorines in the environment and breast cancer. BMJ 1994;308:1520-1.

32 Bach J. The effect of infections on susceptibility to autoimmune and allergic diseases. N Engl J Med 2002;347:91 1-20. 